\title{
LOS DEBERES EN LA CONSTITUCIÓN ESPAÑOLA: ESENCIALIDAD Y PROBLEMÁTICA
}

\author{
MIGUEL ÁNGEL ALEGRE MARTÍNEZ \\ Profesor Titular de Derecho Constitucional \\ Universidad de León
}

\author{
SUMARIO \\ I. Introducción. \\ II. La complementariedad de derechos y \\ deberes. \\ III. Los que son y los que están. \\ IV. ¿A quién y frente a quién obligan? el \\ problema de su exigibilidad. \\ V. Conclusiones.
}

\section{INTRODUCCIÓN}

Durante estos primeros treinta años de vigencia de la Constitución de 1978, ha resultado significativa (por utilizar un término más neutro que "sintomática") la muy superior atención dedicada a los derechos, tanto cuantitativa como cualitativamente, en comparación con la dispensada a los deberes. Quizá no podía esperarse otra cosa a la vista del propio Texto constitucional, que acoge los derechos de manera mucho más generosa y algo más pormenorizada, a pesar de que éstos comparten mención en la rúbrica del Título primero, en aparente pie de igualdad ("De los derechos y deberes fundamentales").

No se trata de un fenómeno que pueda afirmarse en exclusiva de nuestra Norma Básica: en un texto emblemático como la Declaración Universal de los Derechos Humanos de 1948, los deberes sólo son mencionados de forma muy genérica al principio y al final ${ }^{1}$. Y, por ceñirnos al contexto español, algo

1 En un contexto en el que se pretendía la salvaguarda del individuo tras los horrores del reciente conflicto bélico, se consideró que la tarea encomendada consistía en proclamar derechos y libertades, y no en enumerar obligaciones. Al respecto, MARINA y De LA VÁlgOMA, La lucha por la dignidad. Teoría de la felicidad política, Barcelona, Anagrama, 2000, págs. 225-226. 
parecido se observa en nuestro constitucionalismo histórico: si por lo general las constituciones españolas del siglo XIX (con la excepción del Estatuto Real de 1834) recogían "catálogos de derechos más o menos sistematizados" (por más que en la práctica quedaran supeditados a lo que en cada caso estableciera el legislador y fueran frecuentemente suspendidos) ${ }^{2}$, su referencia a los deberes y obligaciones resulta mucho más escueta ${ }^{3}$.

La propia Declaración francesa de los Derechos del Hombre y del Ciudadano de 1789, en su célebre artículo 16 ("Toda sociedad en la que la garantía de los derechos no esté asegurada, ni la separación de poderes determinada, carece de constitución") no menciona los deberes ${ }^{4}$. No serían, pues, requisito para la existencia de la constitución en esa acepción del término denominada bistórico-politica o bistórico-decimonónica, consistente en considerar como Constituciones y como Estados constitucionales únicamente aquellos actos y ordenamientos inspirados en las teorías y doctrinas políticas liberales 5 . Lo que ocurre es que, sencillamente, sin deberes no bay derechos (ni, por tanto, constitución): como certeramente se ha afirmado, "exigir derechos va indisolublemente unido con asumir deberes, ya que sin éstos aquellos no son posibles"; así, aunque la Constitución francesa de 1791, no incluyó referencia alguna a los deberes, en la de 1795 ya se corrigió la omisión ${ }^{6}$.

Sea como fuere, resulta evidente en general el protagonismo de los derechos frente a los deberes, tanto a nivel de presencia en los textos constitu-

2 Jiménez Asensio, El constitucionalismo. Proceso de formación y fundamentos del Derecho Constitucional, Madrid, Marcial Pons, 3. ${ }^{a}$ ed., 2005, págs. 191-192.

3 Así, aparte de obligaciones difícilmente exigibles (las del "amor a la Patria", o el "ser justos y benéficos") y/o genéricamente formuladas (las de "ser fiel a la Constitución, obedecer las leyes y respetar las autoridades establecidas") que encontramos en los arts. 6 y 7 de la Constitución de 1812, dos obligaciones de los españoles tienen presencia constante en los demás textos decimonónicos: la de "defender la Patria con las armas cuando sea llamado por la ley" y la de "contribuir en proporción de sus haberes para los gastos del Estado" (v.gr. art. 6 de la Constitución de 1837, ó 28 de la de 1869). La tendencia se repite en el Texto de 1931: dentro del Título III ("Derechos y deberes de los españoles") sólo unos pocos preceptos contienen deberes u obligaciones, si bien aquí se aprecia ya una mayor concreción, y se detectan contenidos reconocibles en la Constitución vigente: valga mencionar en tal sentido el art. 37 ("El Estado podrá exigir de todo ciudadano su prestación personal para servicios civiles o militares, con arreglo a las leyes"), el 43 (deber de los padres de alimentar, asistir, educar e instruir a los hijos), el 46 (el trabajo considerado como "obligación social») o el 48 (carácter obligatorio, además de gratuito, de la enseñanza primaria).

4 La propuesta surgida durante los debates conducentes a esta Declaración en el sentido de incluir junto a ella otra de deberes, no prosperó finalmente en el seno de la Asamblea Nacional. Al respecto, Brage Camazano, Los limites a los derechos fundamentales en los inicios del constitucionalismo mundial y en el constitucionalismo bistórico español. Estudio preliminar de la cuestión en el pensamiento de Hobbes, Locke y Blackstone, México, Universidad Nacional Autónoma de México, Instituto de Investigaciones Jurídicas, 2005, págs. 80 y ss.

5 Cfr. Biscaretti Di Ruffia, Derecho Constitucional, Madrid, Tecnos, 1982 (con traducción, prólogo y notas de LUCAS verdú), pág. 151.

6 Oliver Araujo, "También deberes", publicado en El Día del Mundo, 11 de octubre de 1997, y recogido también en La Constitución día a día, Valencia, Tirant lo Blanch, 2003, págs. 136-138; LozANO, "Sesenta años de deberes humanos", Diario $A B C, 10$ diciembre 2008, pág. 3. 


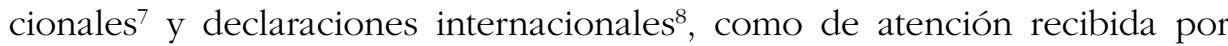
parte de la doctrina y la jurisprudencia? ${ }^{9}$. Las causas de ese fenómeno pueden ser diversas: el desprestigio de la noción de "deber" o la asociación de la misma con la idea de "coacción", su "mala prensa", su "identificación con una limitación de la libertad" o con los sistemas represivos, son algunas de las que se han apuntado, y que sin duda han contribuido a alimentar "un malentendido que nos ha metido en serias dificultades educativas y sociales ${ }^{10}$.

Partiendo de ello, y de la consiguiente necesidad de focalizar los deberes dedicándoles una atención acorde al papel que les corresponde cumplir en nuestro ordenamiento constitucional, creemos que cualquier intento de aportación al servicio de tal objetivo puede ir orientado al menos en dos direcciones. En primer lugar, puede resultar revelador trasladar (o verificar la imposibilidad de hacerlo) al ámbito de los deberes categorías, conceptos o construcciones técnicas suficientemente consolidadas en la esfera de los derechos (y hablar así, por ejemplo, de deberes de la personalidad, eficacia de los deberes frente a los particulares, etc.). Pero no menos interesante puede ser, en segundo término, considerar la dimensión o componente de deber que encierra todo derecho (desde esta perspectiva, por ejemplo, los derechos serían deberes para los poderes públicos, y también los particulares estarían sujetos a un deber genérico de respetarlos). Claro está que ambos caminos no son excluyentes sino complementarios; y también que no se trata tanto de equilibrar una hipotética balanza en la que derechos y deberes estarían en cada uno de los platillos, como de superar esa dicotomía y ofrecer una visión integrada resultante, a fin de cuentas, de aproximarse a los deberes desde el punto de vista de los derechos (en la primera de las líneas de trabajo indicadas) y a los derechos desde la óptica de los deberes (en el caso de la segunda). La adopción de este enfoque debería servirnos para descubrir qué aportan los deberes para ayudarnos a entender los derechos, y qué exigen aquéllos en su condición de instrumentos esenciales para la eficacia de éstos. Y todo ello, por supuesto, no como un mero ejercicio narcisista de especulación teórica que carecería de sentido por agotarse en sí mismo, sino como una búsqueda de la dimensión humana y social de los derechos y los deberes, y de la aplicación conjunta de ambos como piedra angular de la convivencia social constitucionalmente ordenada.

7 Como ejemplos procedentes respectivamente del ámbito europeo y latinoamericano, baste la remisión a la Constitución italiana de 1947 (concretamente su primera parte, "Derechos y deberes de los ciudadanos"), y a la Constitución venezolana de 1999. Véase Mago BendaHÁN, Guía completa de la Constitución 1999 de la República Bolivariana de Venezuela, Caracas, Universidad Pedagógica Experimental Libertador, Paredes Editores, Constitución Activa, 2000.

8 García Cuadrado (Sistema constitucional de Derechos y Libertades, Tomo I, Alicante, Ed. Club Universitario, 3. ${ }^{a}$ ed., 2000, pág. 79).

9 Véase Rubio LloRente, "Los deberes constitucionales", Revista Española de Derecho Constitucional, n ${ }^{\circ}$ 62, 2001, pág. 13, nota 7. sstc 15/1982 de 23 de abril, 6/1983 de 4 de febrero, 37/1987 de 26 de marzo, 160/1987 y 161/1987 de 27 de octubre, 173/1996 de 31 de octubre, entre otras.

10 Marina, Aprender a vivir, Barcelona, Ariel, 2004, pág. 135. 
En esa búsqueda de puntos de confluencia entre derechos y deberes, resulta de utilidad recordar la conocida doctrina sobre la doble naturaleza (objetiva y subjetiva) de los derechos fundamentales, que nuestro Tribunal Constitucional, ya desde sus primeras sentencias, ha incorporado de la doctrina y jurisprudencia alemanas ${ }^{11}$. Si los derechos son elementos esenciales del ordenamiento jurídico y del sistema democrático, y elementos esenciales para la profundización del mismo (hasta el punto de haberse afirmado que "Sin derechos humanos no hay democracia bien entendida") ${ }^{12}$, también podemos considerar como tales a los deberes, en cuanto contrapartida de aquellos, en el entendimiento de que el respeto de los derechos requiere el cumplimiento de los deberes. En este sentido, todos los derechos generarían deberes, aunque no todos los deberes tendrían como contrapartida algún derecho, como veremos en el apartado II.

Asumidas estas premisas, estamos en condiciones de percibir la gran variedad de implicaciones y cuestiones problemáticas asociadas a la consideración de derechos y deberes como las dos caras de una misma moneda (presencia constitucional, complementariedad, enumeración, destinatarios, exigibilidad, aplicaciones concretas, etc). Algunas de ellas podrían agruparse, a efectos sistemáticos y de necesaria delimitación (siguiendo las líneas de trabajo arriba indicadas) en los apartados que dan estructura y contenido a estas páginas.

\section{LA COMPLEMENTARIEDAD DE DERECHOS Y DEBERES}

Si consideramos "derechos de la personalidad" todos aquellos que son imprescindibles para el libre/pleno desarrollo de la misma, esto es, aquellos cuya lesión pueda afectar a ese desarrollo de la personalidad como concreción y exigencia de la dignidad humana ${ }^{13}$, podrán considerarse "deberes de la personalidad" los que vayan dirigidos al objetivo de posibilitar o facilitar ese desarrollo; sin olvidar que la propia existencia de esos derechos genera un deber genérico de respeto que dimana de la propia dignidad ${ }^{14}$. Igualmente, si

11 STC 25/1981 de 14 de julio, y tantas otras. Al respecto, merece la pena volver sobre sCHNEIDER, "Peculiaridad y función de los derechos fundamentales en el Estado constitucional democrático", Revista de Estudios Políticos, n 7, 1979, pág. 23; BÖCKENFÖRDE, Escritos sobre Derechos Fundamentales, Baden-Baden, Nomos Verlagsgesellschaft, 1993 (con prólogo de BASTIDA y traducción de Requejo Pagés y Villaverde Menéndez), págs. 104 y ss.; o Fernández segado, La dogmática de los derechos humanos (A propósito de la Constitución española de 1978), Lima, Ediciones Jurídicas, 1994, págs. 57 y ss.

12 Sánchez Perriz y Jimena Quesada, La enseñanza de los derechos humanos, Barcelona, Ariel, 1995, pág. 13, y págs. 21 y ss.

13 Cfr. arts. 10.1 y 27.2 CE, y art. 29.1 de la Declaración Universal de los Derechos Humanos. Sobre este concepto de los derechos de la personalidad, Alegre Martínez y Mago Bendahán, Derechos de la personalidad y derecho de daños morales, Caracas, Constitución Activa ("Breviarios del nuevo Derecho"), 2007, págs. 20 y ss., 82-100.

14 En un sentido parcialmente distinto (como más adelante se verá) emplea BISCARETTI (Derecho Constitucional, op. cit., pág. 194) esta expresión, "deberes de personalidad", pues la vincula al hecho de ser ciudadano o persona jurídica pública. 
llamamos "derechos innominados" a aquellos susceptibles de ser invocados pese a no estar taxativamente previstos por la Norma Básica, cabe preguntarse si podrá hablarse también de "deberes innominados" para aludir a aquellos cuyo incumplimiento suponga la lesión de uno de esos derechos no expresamente previstos, generando un perjuicio o menoscabo que el ordenamiento jurídico no debería permitir. Estas ideas podrían y deberían entenderse al servicio de una concepción integral de la protección de la persona (también, por tanto, de sus intereses, sentimientos, etc.), que vaya más allá de la mera protección de sus derechos, y no considere cerrada la lista constitucional de derechos y deberes ${ }^{15}$.

No faltan tampoco conexiones entre el tema que nos ocupa y el modelo de organización territorial que la Constitución acoge, el cual, a los efectos que aquí interesan, se basa en el principio de solidaridad entre las diferentes nacionalidades y regiones (art. 2), las consecuencias que del mismo se derivan a la vista del art. 138, y la proclamación del art. 139.1, a cuyo tenor "Todos los españoles tienen los mismos derechos y obligaciones en cualquier parte del territorio del Estado". Por un lado, la obligación de solidaridad entre el Estado y las Comunidades Autónomas y de estas entre sí, "constituye el nexo de unión de los principios de autonomía y unidad, ya que posibilita la realización de la unidad del Estado a partir de la autonomía ${ }^{16}$. Por otro, la previsión constitucional del 139.1 podría hacer cuando menos innecesaria la inclusión en los Estatutos de Autonomía de su propio catálogo de derechos ${ }^{17}$.

Un ejemplo más de la unidad interna que subyace bajo el aparente binomio derechos/deberes, lo encontramos en el ámbito educativo. En este sentido, es preciso que los estudiantes de todos los niveles educativos (que fuera - y también dentro- del aula son, además, personas), perciban que "la buena comprensión de lo que es un derecho no nos encierra en el egoísmo sino que nos abre a la reciprocidad", encontrando en los deberes su lógica

15 Al respecto, Alegre Martínez y Mago Bendahán, Derechos de la personalidad y derecho de daños morales, op. cit., págs. 35 y ss. Encontramos ejemplos del reconocimiento de esos "derechos innominados", no proclamados expresamente, en el art. 22 de la Constitución venezolana de 1999 o en el art. 3 de la Constitución peruana de 1993. Precedentes más lejanos de esta figura se localizan en el art. 29 de la Constitución española de 1869, que a su vez recibe influencia de la Enmienda IX al Texto norteamericano de 1787.

16 De Asís Rolg, Deberes y Obligaciones en la Constitución, Madrid, Centro de Estudios Constitucionales, 1991, pág. 462.

17 Pueden verse sobre esta controvertida cuestión, entre otros, los trabajos de CANOSA UsERA, "La declaración de derechos en los nuevos Estatutos de Autonomía", Teoría y Realidad Constitucional, n. ${ }^{\circ}$ 20, UNED, 2007 (Monográfico Derechos Fundamentales), págs. 61-115; en el mismo lugar, VillaVERDE MenÉnDEZ, "La intangibilidad competencial de los derechos fundamentales. Forma de Estado y derechos fundamentales", págs. 321-357; asimismo, el intercambio de argumentos mantenido por Díez-Picazo y CaAmaño (Díez-Picazo, "Pueden los Estatutos de Autonomía declarar derechos, deberes y principios??, Revista Española de Derecho Constitucional, n 78, 2006, págs. 63-75; CAAMAÑo, "Sí, pueden (Declaraciones de derechos y Estatutos de Autonomía)", REDC, n. ${ }^{7}$ 79, 2007, págs. 33-46; "De nuevo sobre las declaraciones estatutarias de derechos: respuesta a Francisco Caamaño", REDC, n. ${ }^{\circ}$ 81, 2007, págs. 63-70); o la obra colectiva de Aparicio (ed.), Castellà y EXPÓsito (coords.), Derechos y principios rectores en los Estatutos de Autonomia, Barcelona, Atelier, 2008. 
contrapartida ${ }^{18}$. No podemos, por tanto, dejar de resaltar que "el respeto de los derechos y deberes fundamentales constituye una materia transversal a tener en cuenta por el conjunto de los docentes en todos los ciclos formativos, y especialmente en los escalones iniciales ${ }^{19}$. Ello bien puede hacerse extensivo no sólo a los contenidos de la enseñanza, sino también a la propia dinámica del proceso educativo, en la que «la propia concepción del sujeto de derechos, el estudiante, no puede entenderse si no es a partir de sus obligaciones propias a tal condición": el estudio y el resto de los deberes y obligaciones que "dimanan de la natural relación que une al estudiante con el resto de la comunidad educativa ${ }^{20}$.

Valgan esos ejemplos, tan claramente vinculados al presente y al futuro de nuestra andadura constitucional, para percibir la importancia y la aludida dimensión humana de la presencia de los deberes al lado de los derechos, no sólo en la letra de la Norma Básica, sino en el sentir y actuar colectivos; lo cual, al fin y al cabo, nos reconduce a la consideración de la igualdad en deberes como lógico correlato de la igualdad en derechos. Sólo así podrán darse "las condiciones para que la libertad y la igualdad del individuo y de los grupos en que se integra sean reales y efectivas", cuya promoción es tarea asignada a los poderes públicos por el art. 9.2 CE. La igualdad, que en rigor, más que un derecho ( no tenemos derecho a ser iguales, lo somos sin más") sería el principio del ordenamiento constitucional e internacional del que se parte al reconocer los derechos de todo ser humano $^{21}$, y la libertad en sus distintas versiones y facetas, vertebran todo el sistema de derechos y, por tanto, también de deberes, y forman parte esencial del núcleo axiológico de la Constitución, aunadas con la justicia y el pluralismo político en el art. 1.122. Y lo hacen al servicio de la dignidad humana, reconocida en el art. 10.1 CE como "fundamento del orden político y de la paz social", y concretada entre otros aspectos en "el respeto a los

18 Véase Marina y De la Válgoma, La lucha por la dignidad. Teoría de la felicidad política, op. cit., págs. 189 y ss., 192-197, 229, 269-271. Muchas serían las aplicaciones en las que esta idea puede y debe concretarse: así, la libertad de expresión o la libertad de conciencia no pueden separarse de la exigencia de una actitud tolerante y ajena al fanatismo; el derecho a la participación política mediante el derecho de sufragio llevará consigo el deber cívico (aunque no exigible jurídicamente en España) de votar, contribuyendo así a la formación de la voluntad popular representada en el Parlamento, etc.

19 JimenA QuESADA, "El conocimiento del ordenamiento constitucional: condición necesaria de calidad del sistema educativo", en PeÑa González (coord.), Libro Homenaje a D. Íñigo Cavero Lataillade, Universidad San Pablo-CEU, Ed. Tirant lo Blanch, Valencia, 2005, págs. 383-413, en concreto pág. 402.

20 Cotino Hueso (coord.) y SÁnCHez FerRiz (dir.), Derechos, deberes y responsabilidades en la enseñanza (Un análisis jurídico-práctico a la luz de los dictados constitucionales, Valencia, Consellería de Cultura, Educaciò i Ciència de la Generalitat Valenciana ("Colección de textos Científico Técnicos"), 2000, pág. 259.

21 Sánchez Ferriz y Jimena Quesada, La enseñanza de los derechos humanos, op. cit., pág. 38.

22 Véase FERnández SEgado, "La dimensión axiológica del Derecho Constitucional", Cuadernos de la Cátedra Fadrique Furió Ceriol, 2. ${ }^{a}$ época, n. ${ }^{\circ}$ 1, 1992, págs. 15-39. 
derechos de los demás»²3. Es más: podría afirmarse incluso que "de la propia dignidad humana lo que se desprende no son los derechos sino los deberes del hombre ${ }^{24}$. En suma, la presencia de derechos y deberes en los textos constitucionales, así como el carácter normativo que esa presencia les confiere, obedece a un fundamento común, que no es otro que la persona y su dignidad, y que deja probada su complementariedad y esencialidad en el marco del sistema democrático ${ }^{25}$.

\section{LOS QUE SON Y LOS QUE ESTÁN}

Considerando que "forma parte de la lógica del Estado constitucional [...] que, una vez aprobada la Constitución, el poder constituyente desaparezca, cediendo su lugar a la propia norma por él creada" ${ }^{26}$, habremos de deducir que el efectivo cumplimiento de su obra ya no depende de él: la eventual capacidad de la Constitución para transformar la realidad no queda, pues, en manos del poder constituyente (el cual sólo se reactivará en su día para volver a actuar como tal), sino en el uso y cumplimiento que los poderes constituidos y el conjunto de los ciudadanos hagamos de su obra. Trasladando esta idea al ámbito que ahora nos ocupa, podría afirmarse de manera gráfica que el constituyente español de 1978 hizo los deberes, pero también nos puso deberes, pues la eficacia de los deberes (y de los derechos) constitucionalmente recogidos no depende de ese poder constituyente, sino que su materialización corresponde a "los ciudadanos" y a "los poderes públicos" (en expresión del artículo 9.1 CE).

Como en seguida comprobaremos, los deberes están dispersos a lo largo del Texto constitucional, por lo que no han corrido mejor suerte que los de-

23 En relación con este tema, valga la remisión al estudio que de la dignidad de la persona hemos llevado a cabo en trabajos anteriores y a la bibliografía en ellos citada: AlEGRE MARTínEZ, "El art. 10.1 de la Constitución como deber genérico de respetar la dignidad y los derechos de la persona", Revista General de Derecho, n. ${ }^{\circ}$ 604-605, Valencia, 1995, págs. 189-222; La dignidad de la persona como fundamento del ordenamiento constitucional español, Secretariado de Publicaciones de la Universidad de León, 1996; "Cultura de derechos, deberes y participación", Revista de Derecho del Tribunal Supremo de Justicia de Venezuela, n. ${ }^{\circ}$ 5, 2002, págs. 3-17; "Apuntes sobre el derecho a la vida en España: Constitución, jurisprudencia y realidad", Revista de Derecho Político, n. ${ }^{\circ}$ 53, UNED, 2002, págs. 337-358; "El reconocimiento constitucional de la dignidad humana: significado y alcance", en PeÑa GonZález (coord.), Libro Homenaje a D. Ínigo Cavero Lataillade, op. cit., págs. 55-70.

24 García Cuadrado, Sistema constitucional de Derechos y Libertades, op. cit., pág. 77. Explica este autor su afirmación en los siguientes términos: "No es el hecho de la muerte de una persona, ni el de sus padecimientos físicos, ni la destrucción de una propiedad, ni la diferencia natural entre los hombres lo que provoca "indignación" por ser "indigno" tal hecho, sino que lo "indignante" es que haya sido un hombre el autor del mismo. Es pues el derecho a la vida el deber de todos de respetar la vida humana y no el derecho a no morir".

25 Véase BiscaRetTi Di RufFia, Derecho Constitucional, op. cit., págs. 672-674.

26 De VeGA, "La reforma constitucional y la problemática del poder constituyente", Madrid, Tecnos ("Temas clave de la Constitución Española"), 1985, pág. 34. 
rechos en lo que se refiere a su ubicación o agrupación sistemática ${ }^{27}$. Ello, sin embargo, no impide que la línea imaginaria que los une sea a la vez (como ya quedó avanzado en apartados anteriores) el alambre sobre el que avanza nuestra convivencia, el hilo del que pende nuestra democracia, el nexo que une libertad y responsabilidad, el apoyo que sustenta los derechos y, por tanto, la columna vertebral de nuestro sistema político. Pues bien, lo que pretendemos a continuación es fijarnos en los deberes recogidos en nuestra Norma Básica, con la pretensión de adoptar un sentido, una perspectiva más amplia de los deberes, desde la cual tendrían cabida muchos más de los que la Constitución considera expresamente como tales, aunque con formulación ciertamente heterogénea. De paso, podremos fijarnos en los diversos criterios de enumeración y clasificación doctrinalmente propuestos, que aportarán elementos valiosos para nuestra reflexión.

Sabemos ya que el Título I CE lleva como encabezamiento "De los derechos y deberes fundamentales", y que la Sección segunda de su Capítulo segundo mantiene esa aparente igualdad en su rúbrica "De los derechos y deberes de los ciudadanos". Sin embargo, dentro de esta Sección se alude únicamente a unos pocos deberes: el "derecho y deber de defender a España" del que se derivarían las obligaciones militares de los españoles, incluyendo la de cumplir la prestación social sustitutoria (art. 30.1 y 2), el de cumplir el "servicio civil para el cumplimiento de fines de interés general" que pueda establecerse, los "deberes de los ciudadanos en los casos de grave riesgo, catástrofe o calamidad pública" (art. 30.4), la contribución de todos "al sostenimiento de los gastos públicos de acuerdo con su capacidad económica", los "derechos y deberes de los cónyuges" (art. 32.2), el "deber de trabajar" junto con el derecho al trabajo (art. 35.1) ${ }^{28}$.

Sin embargo, y como también hemos adelantado, la referencia a los deberes no se circunscribe únicamente a esa Sección, sino que fuera de ella encontramos, por ejemplo: el deber genérico de respetar la ley y los derechos de los demás (art. 10.1), el deber de conocer el castellano (art. 3.1), la obligación de la enseñanza básica (art. 27.4), el deber de los padres de "prestar asistencia de todo orden a los hijos habidos dentro o fuera del matrimonio, durante su minoría de edad y en los demás casos en que legalmente proceda" (art. 39.3), los "derechos y deberes de todos" en orden a "organizar y tutelar la salud pública a través de medidas preventivas y de las prestaciones y servicios

27 Sobre este tema pueden leerse reflexiones recientes en la Encuesta contenida en el citado n. 20 (Monográfico) de Teoría y Realidad Constiutional, págs. 19 y ss. Se incluyen las opiniones de Aguiar De luque, Díez-Picazo, Gómez Montoro, Peces-Barba Martínez y Solozábal Echavarría. Por caminos y argumentos distintos, con los lógicos matices, y desde la perspectiva que proporciona el paso del tiempo, consideran en general correcta y adecuada la sistemática del Título I.

28 Se confirma así, al menos aparentemente, la impresión inicial según la cual "frente a la amplitud con la que se enuncian los derechos, la Constitución es muy concisa en la previsión de deberes constitucionales". Así lo expresa Blanco VALDÉs, Introducción a la Constitución de 1978, Madrid, Alianza Editorial, 2. ${ }^{\mathrm{a}}$ ed., 2006, págs. 225-226. 
necesarios" (art. 43.2), el de conservar el medio ambiente (art. 45.1), la obligación de "comparecer a requerimiento de las Cámaras" (art. 76.2), "cumplir las sentencias y demás resoluciones firmes de los Jueces y Tribunales, así como prestar la colaboración requerida por éstos en el curso del proceso y en la ejecución de lo resuelto" (art. 118) ${ }^{29}$.

Precisamente la diversidad que se observa en el reconocimiento constitucional de los deberes, tanto en lo relativo a la terminología utilizada como desde el punto de vista de sus destinatarios, función, carácter o estructura, hace que cualquier intento de clarificación, delimitación u ordenación en torno a los deberes deba tener en cuenta, al menos, las siguientes variables:

A) Como elemento de partida, podemos fijarnos en la posición doctrinal según la cual tan inexacto sería considerar "deberes" sólo a aquellos que la Constitución denomina literalmente como tales (en singular o en plural, o utilizando alguna otra expresión equivalente), como considerar "deberes constitucionales" a todos los mencionados sin adoptar un criterio que nos permita identificar los que lo serían en sentido estricto ${ }^{30}$. En esta distinción entre los deberes en sentido estricto y los demás (los que son y están, y los que simplemente están), encontramos un primer y valioso criterio delimitador; ahora bien, puesto que esos otros deberes también están en la Constitución bajo diferentes denominaciones y ropajes, necesitaremos considerar también las demás variables en juego.

B) Independientemente de que en la Constitución algunos deberes se presenten de forma autónoma y otros aparezcan mencionados junto a los derechos (como los de los artículos 32 y 43.2), o incluso formulados como derechos-deber (artículos 30.1 ó 35.1), lo cierto es que de todos los derechos se desprenden deberes y obligaciones. Teniendo esto en cuenta, aumentaría considerablemente el elenco de deberes, pues a los "explícitos" ya mencionados, habría que añadir los "implícitos" derivados de los derechos ${ }^{31}$. Y más aún aumentará si en esa lista no sólo damos cabida a los "deberes", sino también a las diferentes "obligaciones" previstas a lo largo del Texto constitucional.

29 Cfr. Blanco VAldés, Introducción a la Constitución de 1978, ibidem; OlIVER ARAuJo, "También deberes", op. cit., pág. 137. Como concreción de este último deber de prestar la colaboración requerida por los tribunales, el artículo $24.2 \mathrm{CE}$ recoge a la vez la obligación de "declarar sobre hechos presuntamente delictivos", y la suspensión o exención de la misma "por razón de parentesco o de secreto profesional", que deberá regularse mediante ley. Así lo hacen notar Merino Merchán, Pérez-Ugena y Coromina, y Vera Santos, Lecciones de Derecho Constitucional, Madrid, Tecnos, 1995, pág. 201. En cuanto al derecho a sustituir la prestación del servicio militar por una prestación social (art. 30.2), Oliver ARAujo, La objeción de conciencia al servicio militar, Madrid, Civitas/Universitat de les Illes Balears, 1993, y STC 160/1987, FJ 3.

30 Véase Rubio Llorente, "Los deberes constitucionales", op. cit., págs. 14 y ss.

31 En este sentido, ReQuejo PAGÉs ("Deberes constitucionales", en Enciclopedia Jurídica Básica, vol. II, Madrid, 1995) menciona, entre otros, los deberes derivados de la función social de la propiedad (art. 33) o de la libertad de empresa (art. 38). (Citado por RuBIo llorente, Los deberes constitucionales, op. cit., pág. 15). 
Aunque unos y otras aparezcan denominados más o menos indistintamente a lo largo del articulado, una mayor precisión terminológica nos llevaría a distinguir entre el deber (término moral, incondicional, fin en sí mismo, no coactivo) y la obligación (término con significado moral o jurídico, condicional, medio para la consecución de un fin o ideal, y con posible connotación coactiva $)^{32}$. Así pues, la nómina constitucional de obligaciones y/o deberes variará considerablemente en función de la lectura más o menos restrictiva que realicemos o los posibles destinatarios que consideremos. No debe extrañar, por tanto, que, a los efectos de este trabajo, creamos preferible un intento de delimitación conceptual en busca de las distintas perspectivas que nos proporcionen una visión lo más cabal posible de nuestro objeto de estudio, a un ensayo de clasificación para añadir a las ya existentes, suficientemente reveladoras e ilustrativas ${ }^{33}$.

C) El número de deberes aumentaría aún si incluimos determinados deberes cívicos, como el de votar (deducible del artículo $23 \mathrm{CE}$ ), u otras obligaciones recogidas legalmente, pero dirigidas a posibilitar el ejercicio de derechos previstos en la propia Constitución. Sería el caso de la obligación jurídica de ejercer la función de presidente o vocal de una mesa electoral (art. 27.1 de la Ley Orgánica 5/1985 de 19 de junio, del Régimen Electoral General), o la de participar en tribunales de jurados (Ley Orgánica 5/1995 de 22 de mayo, del Tribunal del Jurado, modificada también en diversas ocasiones, y que desarrolla la previsión del artículo $125 \mathrm{CE})^{34}$.

D) En diversos lugares la Constitución impone mandatos a los poderes públicos, que bien pueden considerarse deberes genéricos, al lado de otros de carácter más concreto y específico. Si entre los primeros podemos incluir el de

32 De Asís RoIg, Deberes y Obligaciones en la Constitución, op. cit., págs. 64-86, 448 y ss. Algunos ejemplos que menciona este autor: la "obligación de gobierno" (art. 9.3), la "obligación de buen gobierno" (art. 9.2), la solidaridad entre el Estado y las Comunidades Autónomas y de éstas entre sí (art. 2), la de estructura interna y funcionamiento democrático de los partidos, sindicatos y asociaciones empresariales (arts. 6 y 7), o las contenidas, entre otros, en los artículos 27.4, 30.1, $30.4,31.1$, 32.2, 33.2, 103.1, 106, 102 у 108, 133, 134.3, 117, 119, 120, 39.3, 45.1, 46, 49, 50, 51.2, $138,139,149.1 .1^{\mathrm{a}}$, etc.

33 A las distinciones hasta aquí mencionadas entre diferentes categorías de deberes/obligaciones, podemos añadir la que propone Oliver Araujo ("También deberes", op. cit., pág. 137-138) y García CuAdrado (Sistema constitucional de Derechos y Libertades, op. cit., pág. 78. En suma, no todos los deberes tienen el mismo carácter, como tampoco lo tienen todos los derechos ni, más en general, todos los preceptos constitucionales (véase STERN, Derecho del Estado de la República Federal Alemana, Madrid, Centro de Estudios Constitucionales ("Estudios Constitucionales»), 1987 (traducción de Pérez Royo y Cruz Villalón), págs. 265 y ss.

34 A. Ruiz Miguel, "La objeción de conciencia a deberes cívicos", Revista Española de Derecho Constitucional, n. ${ }^{\circ} 47,1996$, págs. 101-124. En cuanto al deber cívico de votar, LÓPEZ GUERRA, "Derechos de participación política", en López Guerra, Espín, García Morillo, Pérez Tremps y Satrústegui, Derecho Constitucional, Volumen I. El ordenamiento constitucional. Derechos y deberes de los ciudadanos, Valencia, Tirant lo Blanch, 7. a ed., 2007, págs. 344-345, que menciona a su vez la sentencia del Tribunal Supremo de 20 de diciembre de 1990. 
sujeción a la Constitución y al resto del Ordenamiento jurídico (art. 9.1, dirigido también a los ciudadanos), o el de promover las condiciones para la libertad e igualdad efectivas, remover los obstáculos para su plenitud y facilitar la participación política, económica, cultural y social (art. 9.2), los mandatos concretos se hallan repartidos, lógicamente, a lo largo de todo el Texto constitucional.

En realidad, en un sentido muy amplio, cada vez que la Constitución prevé una función o una tarea para cualquiera de los órganos o poderes del Estado, le está imponiendo el deber de cumplirlo. Por ejemplo, del art. 66.2 se deduciría el deber de las Cortes de "ejercer la potestad legislativa del Estado", del art. 97 el de dirigir la política interior y exterior y realizar las demás tareas ahí encomendadas, del art. 106.2 el deber indemnizatorio a favor de los particulares por el mal funcionamiento de los servicios públicos, del art. $117.3 \mathrm{el}$ deber de juzgar y hacer ejecutar lo juzgado, dirigido a Jueces y Tribunales, etc. Claro que también podemos pensar en otro tipo de deberes, no ligados a las tareas que esos órganos deben realizar, sino al modo de realizarlas. En el caso del Poder Judicial, tales deberes estarían expresados en forma de "principios": por ejemplo, los Jueces y Magistrados estarían obligados a llevar a cabo sus funciones con independencia, responsabilidad, etc. (art. 117.1). De la misma manera, para la Administración deduciríamos el deber de responsabilidad, objetividad, actuación en defensa de los intereses generales (arts. 103.1, 106.2). Y en esta muestra en absoluto exhaustiva, encontraríamos también, para la persona del Rey, el deber de «desempeñar fielmente sus funciones, guardar y hacer guardar la Constitución y las leyes y respetar los derechos de los ciudadanos y de las Comunidades Autónomas", junto con el deber de prestar juramento al ser proclamado ante las Cortes Generales de que así lo hará (art. 61.1). El párrafo siguiente del mismo artículo, impone esos mismos deberes al Príncipe heredero al alcanzar la mayoría de edad, junto con el de jurar fidelidad al Rey (y por tanto, efectivamente guardársela). El deber de juramento o promesa está presente también en el acceso a las funciones públicas y representativas ${ }^{35}$.

E) Si de mandatos o deberes genéricos hablamos, no podemos dejar de mencionar los contenidos en el Preámbulo constitucional, presentados bajo la forma objetivos que "la Nación Española" "proclama su voluntad" de lograr:

35 En la Constitución italiana ese deber genérico de fidelidad a la República, observancia de la Constitución y las leyes, y juramento de cumplir con "disciplina y honor" las funciones públicas encomendadas, se encuentra en el artículo 54. En el mismo contexto italiano, la idea del tipo de deberes ligados al cumplimiento de funciones públicas parece recogida dentro de lo que BiscARETTI (Derecho Constitucional, op. cit., págs. 194-195), denomina "deberes públicos". Más en concreto, distingue, entre los principales "deberes de personalidad", los que "derivan de ser ciudadano (como el deber de fidelidad al propio Estado) o persona jurídica pública. Entre los "deberes de función", los de asumir el oficio de juez popular; estarían también los deberes políticos (el de voto, configurado como deber cívico), o los deberes de prestación, algunos de los cuales alcanzan a todos los ciudadanos (servicio militar, trabajo, pago de tributos) y otros de carácter especial. 
consolidar un Estado de Derecho, promover el progreso de la cultura y de la economía para asegurar a todos una digna calidad de vida, establecer una sociedad democrática avanzada, etc. No se trata de entrar en los conocidos debates sobre la conveniencia de incluir un preámbulo en las constituciones, o sobre el eventual carácter normativo del mismo. Únicamente, dejando a salvo su "indudable y decisivo" valor "como criterio interpretativo fundamental de la Constitución" "36, nos conformaremos aquí con apuntar que la consideración conjunta de los contenidos del preámbulo con aquellos artículos en los que cada uno de ellos se proyecta y a cuya interpretación contribuye (baste citar algunos ejemplos ilustrativos, como el propio artículo 9 ó, en general, los "Principios rectores de la política social y económica" contenidos en el Capítulo III del Título I) ${ }^{37}$, resulta especialmente oportuna a la hora de identificar mandatos a los poderes públicos de los que se deducen numerosas aplicaciones concretas en ese ámbito de los deberes en sentido amplio. Por ejemplo, la mención preambular a la "digna calidad de vida" encontraría proyección, entre otros, en los arts. 15 (derecho a la vida), 43 (protección de la salud), 44 (acceso a la cultura), 45 (disfrute del medio ambiente adecuado), 47 (vivienda digna), 51 (defensa de los consumidores y usuarios), etc.; sin olvidar que mientras no se dé el necesario respeto a la vida humana (cuestión a la que ya se aludió al final del apartado II) carecerá de sentido todo lo demás.

F) En esa nómina de deberes genéricos, ocupan un papel destacado y especialmente relevante los recogidos en los artículos 10.1 y 30.4. Respecto de este último ("Mediante ley podrán regularse los deberes de los ciudadanos en los casos de grave riesgo, catástrofe o calamidad pública") hay que recordar - por mantener el referente comparativo que venimos utilizando- su similitud con el citado art. 23 de la Constitución italiana en cuanto al establecimiento de una reserva de ley como garantía frente a la imposición de prestaciones personales o patrimoniales ${ }^{38}$.

36 SÁnchez Ferriz, El Estado constitucional y su sistema de fuentes, Valencia, Tirant lo Blanch, 3. ${ }^{\text {e }}$ ed., 2005, págs. 197-199. Véase también para una referencia específica a lo que ha dado de sí el preámbulo español en el plano doctrinal e interpretativo-jurisprudencial, TAJADURA TejadA, El preámbulo constitucional, Granada, Comares, 1997; y, del mismo autor, "Veinticinco años de Preámbulo constitucional", Revista de Derecho Político, n. ${ }^{\circ}$ 58-59, uned, 2003-2004, págs. $29-46$.

37 Véase J. Tajadura Tejada (dir.), Los principios rectores de la politica social y económica, Madrid, Biblioteca Nueva, 2004, con prólogo de GARCía HERrERA.

38 La doctrina se ha ocupado de confrontar el párrafo 4 del art. 30 CE y el anterior, en virtud del cual "Podrá establecerse un servicio civil para el cumplimiento de fines de interés general". Ambos tendrían en común la necesidad de desarrollo por parte del legislador para que este tipo de obligaciones puedan imponerse a los ciudadanos (por más que en el párrafo 3 no se establezca expresamente la reserva de ley). La diferencia estribaría fundamentalmente "en el carácter regular o periódico que la Constitución parece asociar al servicio contemplado en el apartado 3 (al estilo del servicio militar y la prestación social sustitutoria), frente al carácter eventual de los deberes a los que se refiere el apartado 4, que viene determinado por la propia excepcionalidad de las circunstancias que los justifican". Aun así, cabría hablar de una "común naturaleza de todos los deberes contemplados en los distintos apartados del art. 30 de la CE, caracterizados por plas- 
En cuanto al artículo 10.1, nos interesa aquí específicamente el respeto a la ley y a los derechos de los demás como proyección y consecuencia de la proclamación de la dignidad de la persona que da sentido y unidad a todo el precepto. El inciso concreto que nos ocupa, permite situar debidamente el reconocimiento de la dignidad humana en el contexto del Estado social y democrático de Derecho al que se alude desde la propia norma constitucional de apertura, y configura la dignidad (y el obligado respeto a los derechos inherentes a la persona derivados de la misma) no sólo como fundamento, base y razón de ser de esos derechos, sino también como fin último del reconocimiento de los mismos y del establecimiento de garantías, y también como limite de los derechos, del que se deduce a su vez el deber genérico al que ahora nos referimos ${ }^{39}$. Vemos que el respeto a los derechos de los demás es a la vez en la Constitución un límite y un deber ${ }^{40}$.

marse en obligaciones de hacer que se establecen por razones de interés general, bien sea con carácter estable, bien con carácter ocasional" (Espín, "Los deberes constitucionales", en López GuErra, Espín, García Morillo, Pérez Tremps y Satrústegui, Derecho Constitucional, Volumen I. El ordenamiento constitucional. Derechos y deberes de los ciudadanos, op. cit., pág. 210). Si acaso, añadiríamos el carácter más amplio e impreciso con que aparece prevista la imposición de deberes en el párrafo 4, dejando al legislador un mayor margen de apreciación a la hora de concretar la previsión constitucional. El artículo 30.4 ha encontrado desarrollo legislativo en la Ley Orgánica 4/1981 de 1 de junio, de los estados de alarma, excepción y sitio, y en la Ley 2/1985 de 21 de enero, de Protección Civil.

39 Este planteamiento se encuentra desarrollado en Alegre MARTínez, La dignidad de la persona como fundamento del ordenamiento constitucional español, op. cit., págs. 74 y ss. y 86 ss., poniéndose de manifiesto que tal deber genérico obliga tanto a los particulares (págs. 86 y ss.) como a los poderes públicos (págs. 107 y ss.).

40 Claro está que en el plano conceptual los límites de los derechos no son equivalentes a los deberes: en efecto, los derechos tienen o encuentran límites, mientras que generan deberes. Pero en el caso concreto que nos ocupa, la dignidad y su proyección en el respeto a los derechos de los demás participan simultáneamente de ambas cualidades. En todo caso, interesa destacar que el respeto a ese deber y ese límite, su cumplimiento y efectividad, estará garantizado en la medida en que lo estén los derechos que deben ser respetados. Lo mismo ocurre en general con aquellos deberes presentes en la Constitución (independientemente de que se les denomine así expresamente) que se encuentran estrechamente vinculados a un derecho correlativo constitucionalmente protegido: por ejemplo, el cumplimiento de la obligación de seguir la enseñanza básica (art. 27.4) estará garantizado en la medida en que lo esté el derecho a la educación. E igualmente ocurrirá con los límites de los derechos (por ejemplo, los previstos en los arts. 16.1 ó 20.4 CE), ya que llevan implícito el deber de respeto a los mismos. De nuevo los deberes genéricos nos permiten extraer consecuencias válidas y aplicables para deberes específicos. Como obra de referencia en torno a los límites, Brage Camazano, Los límites a los derechos fundamentales, Madrid, Dykinson, 2004.

En cuanto a la idea de que sólo los fines o límites constitucionalmente reconocidos pueden limitar los derechos, en virtud del principio de unidad de la Constitución (la cual no podría "vaciarse" por medio de normas que carezcan de su rango), y que por nuestra parte consideramos trasladable también al ámbito de los deberes sin perjuicio de lo que en seguida se indicará, ha sido frecuentemente utilizada por el Tribunal Constitucional (por ejemplo, STC 154/2002 de 18 de julio, fu 8). Véase de nuevo Brage Camazano, Los límites a los derechos fundamentales, op. cit., págs. 369 y ss., y la opinión diferente de JimÉNEZ CAMPO (Derechos fundamentales. Concepto y garantías, Madrid, ed. Trotta, 1999, págs. 38 y ss., 74 y ss.) allí recogida. En torno a la misma idea, aplicada a un contexto diferente, Brage Camazano, Recensión a DoméneCh Pascual, Bienestar animal contra derechos fundamentales (Barcelona, Atelier, 2004), en Boletín Mexicano de Derecho Comparado, n. 122, mayo 2008, pág. 1119. http://www.ejournal.unam.mx/bmd/bolmex122/BMD000012222.pdf. 
G) Si la adopción de distintos enfoques o perspectivas nos ha permitido en estas páginas ampliar el concepto de "deber" para dar cabida dentro del mismo a muchos contenidos constitucionales que no aparecen considerados expresamente como deberes, el siguiente paso en esta dirección nos permitiría llevar esa ampliación casi hasta sus últimas consecuencias; ya que, lo visto hasta aquí, nos permite afirmar que todos los derechos generan deberes, o que, incluso, son deberes. Se ha escrito en tal sentido que "hablar de derechos es siempre hablar de deberes, porque la consagración de cualquier derecho constitucional implica siempre la imposición de una serie de deberes para los poderes públicos e indirectamente para los ciudadanos ${ }^{41}$.

Por supuesto, esta consideración general de los derechos como deberes no es incompatible con la presencia constitucional de auténticos deberes para los poderes públicos, aunque se presenten en forma de "criterios" que deben orientar su actuación: nos estaríamos refiriendo al art. 31.2 CE, en virtud del cual "El gasto público realizará una asignación equitativa de los recursos públicos y su programación y ejecución responderán a los criterios de eficiencia y economia". Es obvio igualmente que muchos mandatos a los poderes públicos (como el contenido en el art. 9.2, sin ir más lejos) están ubicados constitucionalmente fuera del Título I (como, por otra parte, sucede también con otros contenidos constitucionales que encierran o implican derechos, como los artículos 121 ó 129.2, entre otros). Pero es que, además, los deberes de los particulares generan correlativamente deberes para los poderes públicos. Por ejemplo: el deber de contribuir al sostenimiento de los gastos públicos (art. 31.1) generaría el deber de administrar esos recursos de manera transparente, honesta, austera y eficaz, aunque eso sea más de lo que expresamente dice el artículo 31.2.

H) Ello nos conduce directamente al último paso en nuestra búsqueda: además de los deberes que son y están, ¿existe fundamento para afirmar la posibilidad de deducir deberes constitucionales que no están en la Constitución, ni denominados expresamente como tales ni presentes bajo otro tipo de formulaciones? ¿Cabe establecer un paralelismo con los llamados derechos innominados, susceptibles de ser añadidos a los constitucionalmente previstos?

Podría cuestionarse la oportunidad de estas preguntas siendo ya tantos los deberes y obligaciones extraibles del tenor literal de nuestra Norma Básica. Incluso, no faltarían razones para negar la posibilidad de tales deberes. Se argumentaría, por ejemplo, que no es lo mismo admitir nuevos derechos que imponer nuevos deberes, de la misma manera que, por ejemplo, en el ámbito penal, se admite como atenuante "cualquier otra circunstancia de análoga significación que las anteriores" (art. 21.6 del Código Penal), pero no existe una ampliación analógica similar para las circunstancias agravantes en el artículo 22. Igualmente, el Código Civil, tras definir la analogía en su artículo 4.1 («Procederá la aplicación analógica de las normas cuando éstas no contem-

41 García CuAdrado, Sistema constitucional de Derechos y Libertades, op. cit., pág. 78. 
plen un supuesto específico, pero regulen otro semejante entre los que se aprecie identidad de razón") la excluye para las leyes penales en el apartado siguiente.

Creemos sin embargo que la coherencia con la posición que aquí venimos explicando, en torno a la superación del binomio derechos/deberes como categorías antagónicas o contrapuestas y su consideración como complementarios, nos lleva a defender la posibilidad de nuevos deberes que nazcan, deriven o traigan causa de nuevos derechos ${ }^{42}$, cuya eficacia vendrá marcada por la necesidad de su obligado respeto. Tal y como adelantábamos al comienzo del apartado I, la aceptación de la figura de los derechos innominados y la consiguiente posibilidad de invocarlos legalmente, con la debida y necesaria cobertura del sistema constitucional de garantías a pesar de no estar esos nuevos derechos taxativamente previstos en la Norma Básica, supone una loable ampliación de nuestro horizonte y la superación de un encorsetado formalismo. La adquisición del "rango" constitucional por parte de esos nuevos derechos le vendría dada, precisamente (a falta de mención expresa en el Texto), por la aplicación a los mismos del sistema constitucional de garantías; y ese mismo rango adquiriría el deber de respeto de esos derechos, así como los límites de los mismos, y los límites que esos derechos supusieran para otros ${ }^{43}$. Asimismo, la entidad constitucional de esos nuevos derechos y deberes derivaría de su común fundamento en la dignidad humana.

\section{IV. ¿A QUIÉN Y FRENTE A QUIÉN OBLIGAN? EL PROBLEMA DE SU EXIGIBILIDAD}

Hemos podido comprobar a lo largo de estas páginas que los deberes constitucionales admiten su doble consideración como «exigibles a los ciudadanos para con la sociedad" en cuanto que "entrañan la existencia de una situación de sujeción que los poderes públicos imponen a los ciudadanos a fin de tutelar intereses de carácter general o bienes que se estiman dignos de protección", y como "impuestos a los poderes públicos", habida cuenta de que

42 Ejemplos en esta línea, necesitados sobre todo de profundización en la práctica, podríamos encontrarlos en el frecuentemente llamado derecho a no emigrar, "es decir, a vivir en paz y dignidad en la propia patria" (JuAn PABlo II, "Mensaje de Su Santidad Juan Pablo II para la Jornada Mundial del Emigrante y del Refugiado", Cáritas, n. ${ }^{4}$ 452, septiembre 2004, pág. 5), o bien en su correlativo derecho a emigrar; también, en el derecho de los emigrantes a vivir dignamente sin ser explotados o sometidos a condiciones infrahumanas, o en el cada vez más insistentemente proclamado derecho a la alimentación suficiente y adecuada (presente ya en el artículo 25 de la Declaración Universal de los Derechos Humanos de 10 de diciembre de 1948, así como en el artículo 11 del Pacto Internacional de Derechos Económicos, Sociales y Culturales de 19 de diciembre de 1966, y en relación con el cual la Organización de las Naciones Unidas ha declarado, entre otros, el objetivo de hambre cero para el año 2015).

43 Alegre Martínez y Mago Bendahán, Derechos de la personalidad y derecho de daños morales, op. cit., págs. 35 y 40-42. 
"la consagración de cualquier derecho constitucional implica siempre la imposición de una serie de deberes para los poderes públicos e indirectamente para los ciudadanos" ${ }^{44}$.

Los derechos son, pues, deberes para los poderes públicos. Es más: «la presencia de la constitución como norma directiva fundamental hace necesaria la definición de deberes sustanciales de los poderes públicos que trascienden la mera defensa y garantía de los derechos y libertades ${ }^{45}$. Ello conectaría con la obligación genérica "de buen gobierno" que entre nosotros se ha situado en el artículo 9.2 de la Norma Básica ${ }^{46}$, y que en el caso que nos ocupa, en cumplimiento del artículo 9.1, se concretaría a su vez en otros dos deberes genéricos destinados a los poderes públicos: el de ejercer las oportunas potestades normativas en desarrollo de los deberes, y el de hacerlos cumplir.

Surge así la necesidad de determinar en qué medida la obligatoriedad jurídica de los deberes está ligada a su desarrollo legislativo. La caracterización de los mismos que hemos visto nos lleva a afirmar su obligatoriedad directamente derivada de la Constitución; y ello no sólo por la imperatividad proclamada en el artículo 9.1, sino también por la defensa del carácter normativo expreso y superior de la Constitución sin necesidad de esperar a su desarrollo legal, reiteradamente señalada por el Tribunal Constitucional: «La Constitución, lejos de ser un mero catálogo de principios de no inmediata vinculación y no inmediato cumplimiento hasta que sea objeto de desarrollo por vía legal, es una norma jurídica [...] y en cuanto tal, tanto los ciudadanos como todos los poderes públicos [...] están sujetos a ella" (SSTC 16/1982 de 28 de abril y 80/1982 de 20 de diciembre). De manera que la inexistencia de una ley de desarrollo no eximiría de la exigibilidad de tales deberes, al nacer éstos de la propia Constitución ${ }^{47}$.

No se trata, pues, de si los deberes obligan a los poderes públicos o a los ciudadanos, pues una cosa no es incompatible con la otra; sino, acaso, de distinguir entre unos deberes y otros en cuanto a que, por su propio contenido, naturaleza o formulación, sean susceptibles de afectar especialmente al individuo o al poder público. En última instancia, el tema se reconduciría al diverso carácter de los preceptos constitucionales y al distinto nivel de garantía en función de su ubicación, como ya se vio en el apartado II. Pero salvada esta premisa, sí puede ser de utilidad realizar alguna consideración adicional

44 Respectivamente, Oliver Araujo, "También deberes", op. cit., págs. 137-138, y García CuAdRADO, Sistema constitucional de derechos y libertades, op. cit., pág. 78.

45 Fioravanti, Los derechos fundamentales. Apuntes de historia de las constituciones, Madrid, Ed. Trotta, Universidad Carlos III, 1996 (con presentación de ÁlvVAREZ Alonso y traducción de MarTíNEZ NeIRA), pág. 131.

46 De Asís Roig (Deberes y obligaciones en la Constitución, op. cit., pág. 453.

47 Esta es la posición mantenida por A. L. y J. A. Alonso De Antonio, Derecho Constitucional Español, Madrid, Ed. Universitas, 1996, a la que se adhiere García-ATANCE y García De Mora (dir. y coord.), Derecho Constitucional III. Derechos y libertades, Madrid, Colex y UNED, 2003, pág. 84 . 
con el fin de clarificar qué aporta el desarrollo legislativo a la idea -así como a la exigibilidad y eficacia- del deber constitucional ${ }^{48}$.

A su vez, esta pregunta acaba desembocando inevitablemente en la doble cuestión de si los deberes obligan a los particulares y si obligan frente a los particulares, habida cuenta de que la Constitución no contempla sanciones para su incumplimiento. Si esa doble vinculación dependiera efectivamente de la existencia de sanciones, habría que concluir que la efectiva sujeción de los ciudadanos a los deberes no podría afirmarse respecto de la Constitución, sino en virtud de la ley que estableciera esas sanciones. Según esta interpretación, los deberes irían dirigidos únicamente a los poderes públicos (destacadamente al legislador), y a ellos correspondería establecer los cauces mediante los cuales los ciudadanos quedaran sujetos a esos deberes ${ }^{49}$.

Ocurre, sin embargo, que la sujeción de los particulares a la Constitución está expresamente afirmada por el ya mencionado artículo 9.1, y por tanto, también los deberes van dirigidos a ellos (lo cual no es necesariamente incompatible con su consideración como destinatarios "últimos", por contraposición a unos poderes públicos que lo serían con carácter inmediato).

Precisamente por eso se hace necesario clarificar la relación que a estos efectos la Constitución establece entre los poderes públicos y los particulares. Para ello, habría que empezar por entender los deberes y obligaciones como aquellos comportamientos positivos o negativos, que se imponen a un sujeto en consideración a intereses que no son particulares suyos, sino en beneficio de otros sujetos e intereses generales de la comunidad ",50; y a partir de ahí, como siguiente paso, retomar la distinción (ya planteada en el apartado II) entre deber y obligación, que es aquí donde encuentra su principal utilidad y significado. Así, en el contexto de los deberes constitucionales que aquí nos ocupa, podemos afirmar que "la Constitución impone a los ciudadanos deberes jurídicos que, con la mediación de la ley, se concretan en obligaciones específicas. En efecto, por lo general la Constitución impone deberes genéricos (el de defender a España, el deber de contribuir al sostenimiento de los gastos públicos) y se remite a la ley para su plasmación en obligaciones concretas para los ciudadanos". De esos deberes constitucionalizados "se deriva un simple sometimiento a la norma constitucional, lo que

48 En relación con la objeción de conciencia como excepción al deber general de prestación del servicio militar, el Tribunal Constitucional señala que es la Constitución la que reconoce ese derecho "de manera implícita y explícita, no significando otra cosa la expresión "la ley regulará" del artículo 30.2 que la necesidad de la interpositio legislatoris, no para reconocer, sino, como las propias palabras indican, para "regular" el derecho en términos que permitan su plena aplicabilidad y eficacia" (STC 160/1987 de 27 de octubre, fu 3). Se trata, pues, de ver la manera de trasladar este razonamiento al ámbito de los deberes; si bien, a estos efectos no arroja excesiva claridad la referencia del Tribunal en el mismo lugar a los "deberes constitucionales o "subconstitucionales"”.

49 Véase RuBio Llorente, “Los deberes constitucionales”, op. cit., pág. 21.

50 Siguiendo a Espín, “Los deberes constitucionales”, en López Guerra, Espín, García Morillo, Pérez Tremps y Satrústegui, Derecho Constitucional, Volumen I. El ordenamiento constitucional. Derechos y deberes de los ciudadanos, op. cit., pág. 202. 
supone una genérica obligación de no obstaculizar su cumplimiento"; mientras que mediante las leyes de desarrollo, "el particular queda obligado a determinados comportamientos concretos jurídicamente exigibles». Así pues, sólo tras la intervención del legislador, surgen obligaciones exigibles por los demás particulares o por la Administración y cuyo incumplimiento puede dar lugar a sanciones" $"$.

Sabemos ya qué aporta a los deberes constitucionales su desarrollo legislativo: la concreción de los mismos en obligaciones, en conductas jurídicamente exigibles. La eficacia normativa del establecimiento de deberes por la Constitución consiste en dar cobertura, poner límite y proporcionar justificación a las obligaciones concretas que el legislador pueda establecer como desarrollo de esos deberes ${ }^{52}$.

Determinada así la vinculación de los poderes públicos (y en concreto del legislador) a los deberes constitucionales, resta añadir que éstos, y las concretas obligaciones en que se traducen, vinculan también a los particulares no sólo frente a los poderes públicos, sino también como consecuencia del deber genérico de respetar los derechos de los demás, al que aludíamos en el apartado II. Si los derechos se tienen frente a los demás, también se tiene frente a los demás el deber de respetarlos. La complementariedad de derechos y deberes que venimos explicando nos lleva a contemplar el incumplimiento de los deberes constitucionales legislativamente traducidos en obligaciones concretas como un menoscabo de los derechos ajenos contrario a lo establecido en el art. 10.1 de la Constitución; y, por supuesto, esas obligaciones no tienen por qué ser exclusivamente frente al poder público, sino que también puede afirmarse de ellas la misma Drittwirkung, eficacia horizontal o frente a terceros, que es posible predicar respecto de los derechos ${ }^{53}$.

En suma, el art. 10.1 CE (respeto a los derechos de los demás como fundamento del orden político y de la paz social) proporciona la necesaria cobertura y justificación constitucional para deducir la eficacia de los deberes frente a los particulares.

\section{CONCLUSIONES}

51 Espín, "Los deberes constitucionales", ibidem.

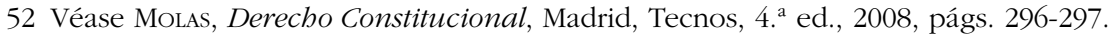

53 En relación con el Ordenamiento español, Cruz Villalón, "Nota: los derechos fundamentales", en La curiosidad del jurista persa, y otros estudios sobre la Constitución, Madrid, Centro de Estudios Políticos y Constitucionales, "Estudios Constitucionales", 1999, págs.247-252; DE VEGA GARCía, "En torno al problema de la eficacia horizontal de los derechos fundamentales", en VV.AA., Estudios de Derecho Público. Homenaje a Juan José Ruiz Rico, Madrid, Tecnos, 1997, vol. I, págs. 333-345. Véanse también sobre el tema los trabajos de: García Torres y Jiménez-Blanco, Derechos fundamentales y relaciones entre particulares: la Drittwirkung en la jurisprudencia del Tribunal Constitucional, Madrid, Civitas ("Cuadernos Civitas"), 1986; BILBAo UbILlos, La eficacia de los derechos fundamentales frente a particulares: análisis de la jurisprudencia del Tribunal Constitucional, Madrid, Boletín Oficial del Estado / Centro de Estudios Políticos y Constitucionales ("Estudios Constitucionales"), con prólogo de JIMÉNEz CAMPO. 
Claro está que, con lo dicho, no termina la problemática en torno a la eficacia de los deberes, sino que ésta cobra una nueva dimensión cuando se piensa en la exigibilidad de los deberes a los poderes públicos, una vez sentado que los tienen. A los particulares le son exigidos por los poderes públicos de acuerdo con su configuración legal según hemos visto; pero ¿cómo se garantiza el cumplimiento de los deberes y obligaciones, constitucional y legalmente fijados, por parte de los propios poderes públicos? No queda más remedio que poner la mirada (y, si acaso, la confianza), en ese "rico arsenal de medidas y controles del poder" que "colocan al Derecho Constitucional en el presente en un lugar preeminente de las ciencias jurídicas y del que cabe predicar su conversión en suprema técnica de la libertad, ${ }^{54}$.

La profundización y el fortalecimiento del mutuo control entre los órganos que conforman el cada vez más intrincado y complejo organigrama político, se revelan, por tanto, como la única solución para que el poder frene al poder. Sin embargo, harto difícil se presenta esa posibilidad en el actual escenario globalizado, en el que la descentralización, la supranacionalización y la mercantilización de la actividad política compiten en el empeño de desdibujar y debilitar el poder estatal. Por eso, si acabamos de comprobar la necesidad de volver a Montesquieu (aunque sea para actualizarlo), tal vez no esté de más también un retorno metodológico a Rousseau, que "supo definirse con radical contundencia ante el internacionalismo y el cosmopolitismo de su tiempo,, 55 .

De todas formas, siendo esto cierto, tampoco se trata de eludir la parte de responsabilidad que a cada cual le pueda corresponder: "la sociedad global sólo puede funcionar razonablemente si cada uno cumple con su deber de forma escrupulosa ${ }^{56}$; es decir, sólo funcionará si todos (poderes públicos y particulares) estamos en nuestro papel, cumplimos los deberes y no evitamos las obligaciones y responsabilidades que aquéllos generan, y a cuya realización nos comprometen. Trasladar esta idea al ámbito pedagógico y convertirla en el eje en torno al cual gire el ejercicio de la docencia en todos los niveles educativos, nos parece una propuesta válida de cara a un estimable modelo de Educación para la ciudadania ${ }^{57}$.

54 De VegA, "El tránsito del positivismo jurídico al positivismo jurisprudencial en la doctrina constitucional", Teoría y Realidad Constitucional, n. ${ }^{\circ}$ 1, UNED, 1998, pág. 68.

Una reciente reflexión sobre la necesidad de adaptar a la realidad del siglo xxi la teoría de la división de poderes formulada por Montesquieu en el siglo XVIII, la encontramos en De Esteban, "La oposición como poder negativo", Diario El Mundo, 4 de noviembre de 2008

55 De Vega García, «Mundialización y Derecho Constitucional: la crisis del principio democrático en el constitucionalismo actual", Revista de Estudios Políticos, n. ${ }^{\circ}$ 100, 1998, pág. 54.

56 Pendás, "A su riesgo y ventura", Diario $A B C, 22$ de agosto de 2008, pág. 3.

57 Sobre esta controvertida asignatura, introducida en España por la Ley Orgánica 2/2006 de 3 de mayo, de Educación, véase VV.AA., Educación para la Ciudadanía, Madrid, CEU Ediciones y Fundación García-Morente, 2008; EmBID Irujo, "La educación para la ciudadanía en el sistema educativo español. Reflexiones jurídicas", Revista Española de Derecho Constitucional, n. ${ }^{\circ} 83$, 2008, págs. 11-56. En relación con lo que en este lugar nos interesa, el art. 23 a) de la ley considera como objetivo de la asignatura, para la enseñanza secundaria, "Asumir responsablemente 
Por otra parte, al finalizar estas páginas estamos en condiciones de percibir que la difícil exigibilidad de los deberes, sobre todo la de su cumplimiento por parte de los poderes públicos, echa por tierra cualquier intento de elaborar una teoría sobre los mismos, o al menos pone en entredicho la utilidad de tal empeño. No llega a tanto lo que aquí hemos pretendido, pero, en cualquier caso, tampoco es lo que más importa: más preocupante aún es que, si eso sucede con los deberes, también sucede en la misma medida con los derechos que se apoyan en ellos. Si los deberes no se cumplen, los derechos no son eficaces, y sólo queda confiar en que sus garantías lo sean en la práctica. Conviene evitar esa brecha en nuestro modelo de convivencia, esa vía de agua capaz de convertir el Estado de Derecho en mera ficción.

\section{TITLE: Duties in the spanish Constitution: Essentiality and problematic.}

ABSTRACT: For understanding the significance of duties in our constitutional system, we must to leave the perception of rights and duties as opposite elements, and going on to think about them as complementary: as two sides of the same coin. With this purpose, we must follow two lines of work: to translate (if possible) to the field of duties some concepts or categories refered to rights, and to think about the dimension of duty included in every right. From this double approach, we can see duties as essential instruments for the effectiveness of rights, and to discover what furnish duties in view of understanding rights. Along this process towards a whole vision of both concepts, we can find a wide diversity of implications and problematic matters that locate us in the presence of a double necessity: on the one hand, to enlarge the concept of duty with the object of making room for many constitutional contents not expressly designated with this noun. In the other hand, in necessary to make concrete the specific obligations in which duties entail as result of the labour of legislator. The scarceness of effective mechanisms to safeguarding the obligatory nature of duties (above all for public powers), isn't only the main problem in which results in any theoretic reflection about duties, but also endangers something so essential in a democratic coexistence model al respect and effectiveness of rights.

Resumen: Para comprender la importancia de los deberes en nuestro ordenamiento constitucional, es necesario abandonar la percepción de los derechos y deberes como elementos contrapuestos, y pasar a considerarlos como complementarios: como dos caras de una misma moneda. Para ello seguimos dos lineas de trabajo: trasladar (cuando ello sea posible) al ámbito de los deberes conceptos o categorías referidos a los derechos, y considerar la dimensión de deber que encierra todo derecho. Desde este doble enfoque, podemos entender los deberes como instrumentos esenciales para la eficacia de los derechos, y descubrir qué aportan aquéllos para ayudarnos a entender éstos. A lo largo de este proceso bacia un entendimiento conjunto de ambos, encontramos

sus deberes, conocer y ejercer sus derechos en el respeto a los demás, practicar la tolerancia, la cooperación y la solidaridad entre las personas y grupos, ejercitarse en el diálogo afianzando los derechos humanos como valores comunes de una sociedad plural y prepararse para el ejercicio de la ciudadanía democrática”. 
una gran variedad de implicaciones y cuestiones problemáticas que nos sitúan ante una doble necesidad: por un lado, ampliar el concepto de deber para dar cabida dentro del mismo a muchos contenidos constitucionales que no están considerados expresamente como "deberes" $Y$, por otro, concretar las obligaciones en que esos deberes se traducen por obra del legislador.

La escasez de mecanismos que aseguren de modo eficaz la exigibilidad de los deberes (sobre todo para los poderes públicos) no sólo es el principal problema en el que desemboca la reflexión teórica sobre los deberes sino que, además, pone en peligro algo tan esencial en un modelo de convivencia democrática como el respeto y la eficacia de los derechos.

KEY WORDS: Constitutional Rights and Duties. Effectiveness and Limits of Rights. Generical Duties and Specifical Obligations. Constitutional Fundament and Legal Development.

Palabras Clave: Derechos y deberes constitucionales. Eficacia y limites de los derechos. Deberes genéricos y obligaciones específicas. Fundamento constitucional y desarrollo legal. 